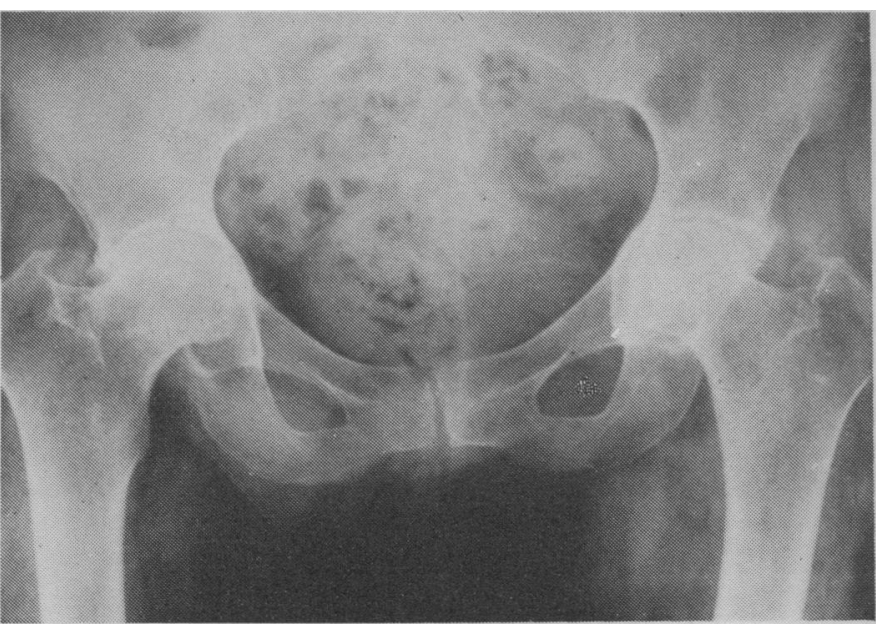

FIG. 4.-Case 1. Radiograph three years after the first and one year after the second operation.

\section{Discussion}

This report aims to assess the place of a relatively minor operation for pain in the hip caused by osteoarthritis and rheumatoid arthritis. In osteoarthritis there was complete relief of pain in $40 \%$ and partial relief in $40 \%$ of cases, but $20 \%$ required further operation within three and a half years. These results compare reasonably favourably with the relief of pain reported from high femoral osteotomy by Osborne and Fahrni (1950) and Nicoll and Holden (1961). We are not advocating this operation for osteoarthritis, but agree with Blount (1964) that it may have a place in the old and frail patient. The results in cases of rheumatoid arthritis are very encouraging. Of 10 cases, eight had complete relief and two partial relief of pain. No patient has either required or wanted further surgery.

There is considerable feeling that high femoral osteotomy is not successful in cases of rheumatoid arthritis. This leaves the main alternative operations of cup arthroplasty and total hip replacement, both of which are major procedures. In our experience and that of Parsons (1969) total replacement in cases of active rheumatoid arthritis has a relatively high rate of complication. Most British surgeons now hesitate to perform total replacement in a young patient with rheumatoid arthritis. Osteotomy of the lesser trochanter, on the other hand, is a relatively simple and safe procedure which can be performed at any age. It does not prejudice the subsequent performance of total replacement.

We cannot explain why this procedure should be effective in cases of rheumatoid arthritis. The work of Layani et al. (1959) suggested that tension in the iliopsoas muscle could be an important source of pain in the hip, and, as already mentioned, four patients with protrusio acetabulae in his series had good results. Benjamin (1969) showed that double osteotomy (osteotomy of the lower femur and upper tibia) could cause regression of rheumatoid synovitis of the knee joint. We feel that for some obscure reason division of bone in the neighbourhood of the hip joint may cause a similar regression.

We would like to thank Mr. J. N. Wilson for permission to follow-up cases under his care and for encouragement in writing this paper. We also wish to thank Mr. Whitley for the photographs and Mrs. Glen Haig and the secretarial staff at the Royal National Orthopaedic Hospital for their help.

Proprietary preparations of the drugs mentioned in this article include: Fastocain, Lidothesin, Xylocaine (lignocaine with adrenaline); Butaphen, Butazolidin, Butazone, Flexazone, IA But (phenylbutazone).

\section{REFERENCES}

Benjamin, A. (1969). Fournal of Bone and foint Surgery, 51B, 694. Blount, W. P. (1964). Fournal of Bone and foint Surgery, 46A, 1297. Cordier, G., Layani, F., and Garnier, H. (1960). Revue du Rhumatisme et des Maladies Ostéo-Articulaires, 27, 337.

Layani, F., Cordier, G., Garnier, H., Roeser, J., and Paquet, J. (1959). Rhumatologie, 11, 223.

Nicoll, E. A., and Holden, N. T. (1961). Fournal of Bone and foint Surgery, 43B, 50 .

O'Malley, A. G. (1959). Fournal of Bone and foint Surgery, 41B, 888.

Osborne, G. V., and Fahrni, W. H. (1950). Fournal of Bone and foin Surgery, 32B, 148 .

Parsons, D. W. (1969). Fournal of Bone and foint Surgery, 51B, 564.

Voss, C. (1956). Münchener medizinische Wochenschrift, 98, 954.

\title{
Immediate Effect on Cardiac Output of Reversion to Sinus Rhythm from Rapid Arrhythmias
}

\section{J. S. WRIGHT,* M.B., M.R.C.P. ; J. FABIAN, $\$ M.D. ; E. J. EPSTEIN, $\ddagger$ M.D., M.R.C.P.}

Ummary: Cardiac output was estimated immediately before and after conversion to sinus rhythm in nine patients with rapid arrhythmias. Conversion was by synchronized direct-current shock in eight patients, and by direct atrial wall stimulation in the other. In seven patients there was an immediate increase in cardiac output after restoration of sinus rhythm. The percentage increase in output was directly proportional to the rate of the arrhythmia immediately before conversion $(r=0.91$, $\mathbf{P}<0.01)$. The critical heart rate, above which an immediate increase in cardiac output might be expected on conversion to sinus rhythm, appeared in these patients to be about 160 beats per minute.

\footnotetext{
* Senior Medical Registrar.

† Late Medical Registrar.

$¥$ Consultant Physician.

Liverpool Regional Cardiac Centre, Sefton General Hospital, Liverpool 15.

Present address: First Medical Clinic, Charles University, Vlasska 36, Prague 1, Czechoslovakia.
}

\section{Introduction}

The use of synchronized direct-current shock as described by Lown et al. (1962) is now generally accepted as an effective way of dealing with most cardiac arrhythmias (Friedberg, 1966). Where an arrhythmia such as atrial fibrillation is slow or is readily controlled by drugs, electrical conversion is an elective procedure, and its success, in terms of a prolonged or permanent return to sinus rhythm, is largely a matter of selection of patients. It is now clear that lasting success will be obtained only when the underlying cause of the arrhythmia has been removed, as after mitral valvotomy or the control of thyrotoxicosis. At the other end of the scale are rapid, uncontrollable tachycardias of ventricular or supraventricular origin, which are followed by obvious deterioration in the condition of the patient, with hypotension, pulmonary oedema, and disturbance of consciousness. Here electrical conversion is undertaken as a life-saving emergency procedure, and there is little difficulty selecting patients. We have been 
interested in a group of patients who fall between these two categories where the tachycardia is rapid and prolonged, and yet the patient seems to tolerate it well with little to suggest seriously impaired cardiac performance. How long can one afford to wait with such patients before undertaking electrical conversion? To what extent is the tachycardia detrimental to cardiac output, and what immediate gain can be expected on return to sinus rhythm? We could find no published studies of this particular group, and so have investigated the effect of conversion on cardiac output in nine such patients.

\section{Patients and Methods}

Details of the nine patients studied are shown in Table I. There were eight males and one female aged 15 to 71 years. Five had no cardiac lesion other than the paroxysmal tachycardia or a Wolff-Parkinson-White (W.P.W.) syndrome, two had W.P.W. syndrome combined with mild valvar or ischaemic lesions, and two had ischaemic heart disease, complicated in one by respiratory infection. When in sinus rhythm none of these patients had greater than grade 2 disability on the New York Heart Association (1964) grading (mild impairment of effort tolerance noticeable only on more strenuous exertion). The ventricular rates ranged from 136 to 264, and the duration of the arrhythmia from 30 minutes to several weeks.

One patient (Case 1) with very rapid atrial flutter: had varied in his ventricular response over the period of observation with rates of 180 to 260 . Two had a ventricular tachycardia, confirmed by intra-atrial E.C.G., and the remainder had supraventricular rhythms. None was appreciably hypotensive, and none, clinically or radiologically, in cardiac failure. Cases 2 and 4 had been treated with lignocaine by infusion, otherwise none had received specific cardiac therapy for 24 hours before conversion. Conversion was by synchronized D.C. shock in eight patients by means of a Lown Cardioverter. Energy applied varied from 80 to 200 joules and up to four shocks were given. This was carried out under light general anaesthesia with methohexitone sodium only, lasting for less than five minutes. Case 7 developed a nodal tachycardia during a catheter investigation of his portal hypertension and reverted to sinus rhythm during manipulation of the catheter in the right atrium.

Cardiac output was measured by the dye-dilution method, using indocyanine green, a Gilford cuvette densitometer (103 1.R.), and constant flow system. Under local anaesthesia fine polyethylene catheters were introduced percutaneously, by the Seldinger (1953) technique, one into either the radial or femoral artery, and one through an antecubital vein into the right atrium. Injections of $5 \mathrm{mg}$. of dye were made into the right atrium, with sampling from the arterial line. Cardiac output calculations were made by the method of Hamilton $e t$ al. (1932), and calibration was carried out with whole blood.
Two or three estimations were made before conversion, before and after induction of anaesthesia, one immediately after conversion to sinus rhythm, and one five minutes later. In some cases a further estimation was made 10 minutes after conversion. Heart rate was measured from an E.C.G. run concurrently with each dye curve.

\section{Results}

The results of conversion to sinus rhythm are shown in Table II. The fall in heart rate ranged from 30 to 156 beats per minute (average 80). The figures shown for cardiac output are the average of the two or three estimations before conversion and the two or three after conversion respectively. Any dye curves not of good quality were rejected. The regurgitant valvar lesions in Cases 3 and 9 were very mild, and there was no distortion of the down-slope exponentials of their dye curves. The preconversion output was lowest in the patient (Case 1) who had the fastest and most prolonged tachycardia. This very low output was recorded in an undersized youth of 15 years and of small weight, but three dye

Table II.-Haemodynamic Findings Before and After Conversion to Sinus Rhythm

\begin{tabular}{|c|c|c|c|c|c|c|c|}
\hline \multirow[b]{2}{*}{$\begin{array}{l}\text { Case } \\
\text { No. }\end{array}$} & \multicolumn{3}{|c|}{ Before Conversion } & \multicolumn{4}{|c|}{ After Conversion } \\
\hline & $\begin{array}{c}\text { Heart } \\
\text { Rate/ } \\
\text { Minute }\end{array}$ & \begin{tabular}{|l|} 
Cardiac \\
Output \\
(1./min.)
\end{tabular} & $\begin{array}{c}\text { Stroke } \\
\text { Volume/ } \\
\text { ml. }\end{array}$ & $\begin{array}{c}\text { Heart } \\
\text { Rate/ } \\
\text { Minute }\end{array}$ & \begin{tabular}{|c|} 
Cardiac \\
Output \\
(1./min.)
\end{tabular} & $\begin{array}{l}\text { \% Increase } \\
\text { in Cardiac } \\
\text { Output }\end{array}$ & $\begin{array}{c}\text { Stroke } \\
\text { Volume/ } \\
\text { ml. }\end{array}$ \\
\hline $\begin{array}{l}1 \\
2 \\
3 \\
4 \\
5 \\
6 \\
7 \\
8 \\
9\end{array}$ & $\begin{array}{l}264 \\
200 \\
168 \\
220 \\
140 \\
190 \\
136 \\
170 \\
160\end{array}$ & $\begin{array}{l}1.83 \\
6.10 \\
5.15 \\
6.31 \\
4.98 \\
3.25 \\
7.37 \\
6.05 \\
3.12\end{array}$ & $\begin{array}{r}6.9 \\
30.5 \\
30.7 \\
28.7 \\
35.6 \\
17.1 \\
54.2 \\
35.6 \\
19.5\end{array}$ & $\begin{array}{r}108 \\
96 \\
120 \\
100 \\
110 \\
110 \\
84 \\
128 \\
80\end{array}$ & $\begin{array}{l}3.09 \\
7.35 \\
5.79 \\
7.75 \\
4.34 \\
4.60 \\
6.23 \\
6.35 \\
3.59\end{array}$ & $\begin{array}{r}68 \\
20 \\
12 \\
23 \\
-13 \\
41 \\
-15 \\
5 \\
15\end{array}$ & $\begin{array}{l}28.6 \\
76.6 \\
48.3 \\
77.5 \\
39.5 \\
41.8 \\
74.2 \\
49.6 \\
44.9\end{array}$ \\
\hline Mean & 183 & 4.91 & $28 \cdot 7$ & 104 & $5 \cdot 45$ & 11 & 53.4 \\
\hline
\end{tabular}

curves were recorded before conversion, and all were of good quality. The rhythm in this patient was atrial flutter with $1: 1$ conduction at the time of conversion, but the degree of block had been variable, and the observed heart rate had ranged from 180 to 260 . It seems unlikely that the cardiac output had been as low as this for the whole period of the arrhythmia. The highest preconversion cardiac output was recorded in the patient (Case 7) who had the slowest rate and shortest duration of tachycardia. There was otherwise no clear relationship between rate or duration of arrhythmia and cardiac output before conversion.

After conversion there was a mean increase for the whole group of $0.541 . / \mathrm{min}$. in cardiac output and of $24.7 \mathrm{ml}$. in stroke volume. In Cases 5 and 7 there was a slight fall in cardiac output after conversion. Both had functionally normal hearts and ventricular rates less than 160 beats per minute before conversion. Seven patients showed an increase in car-

TABLE I

\begin{tabular}{|c|c|c|c|c|c|c|c|c|c|}
\hline \multirow[b]{2}{*}{ Case No. } & \multirow{2}{*}{$\begin{array}{l}\text { Age and } \\
\text { Sex }\end{array}$} & \multirow[b]{2}{*}{ Diagnosis } & \multirow{2}{*}{$\begin{array}{c}\text { Functional } \\
\text { Classification } \\
\text { Before } \\
\text { Tachycardia* }\end{array}$} & \multirow[b]{2}{*}{ Type of Arrhythmia } & \multirow{2}{*}{$\begin{array}{c}\text { Approximate } \\
\text { Duration }\end{array}$} & \multirow{2}{*}{$\begin{array}{c}\text { Ventricular Rate } \\
\text { Immediately Prior to } \\
\text { Conversion Beats } \\
\text { Per Minute }\end{array}$} & \multicolumn{3}{|c|}{ Clinical State During Paroxysm } \\
\hline & & & & & & & Dyspnoea & $\begin{array}{l}\text { Blood } \\
\text { Pressure } \\
\text { mm. Hg }\end{array}$ & $\begin{array}{c}\text { Basal } \\
\text { Crepita- } \\
\text { tions }\end{array}$ \\
\hline 1 & $15 \mathrm{M}$. & Idiopathic paroxysmal tachy- & 1 & Atrial flutter & 6 weeks & 264 & 0 & $105 / 80$ & $\mathbf{0}$ \\
\hline $\begin{array}{l}2 \\
3\end{array}$ & $\begin{array}{l}29 \mathrm{M} . \\
31 \mathrm{M}\end{array}$ & $\begin{array}{l}\text { W.P.W. } \\
\text { Mild mitral regurgitation. } \\
\text { W.P.W. }\end{array}$ & $\begin{array}{l}1 \\
2\end{array}$ & $\begin{array}{l}\text { Ventricular tachycardia } \\
\text { Atrial fibrillation }\end{array}$ & $\begin{array}{l}1-2 \text { weeks } \\
2 \text { hours }\end{array}$ & $\begin{array}{l}200 \\
168\end{array}$ & $\begin{array}{l}\mathbf{0} \\
0\end{array}$ & $\begin{array}{l}100 / 70 \\
120 / 80\end{array}$ & ? \\
\hline 4 & $54 M$. & Ischacmic heart disease. No & 2 & Ventricular tachycardia & 30 minutes & 220 & Slight & $120 / 80$ & $\mathbf{0}$ \\
\hline 5 & $56 \mathrm{M}$. & Idiopathic paroxysmal tachy- & 1 & Atrial fibrillation & 48 hours & 140 & $\mathbf{0}$ & $130 / 80$ & $\mathbf{0}$ \\
\hline 6 & $63 \mathrm{~F}$. & $\begin{array}{l}\text { cardia } \\
\text { cardia }\end{array}$ & 1 & Nodal tachycardia & 12 hours & 190 & 0 & $100 / 70^{\circ}$ & 0 \\
\hline $\begin{array}{l}7 \\
8\end{array}$ & $\begin{array}{l}50 \mathrm{M} . \\
71 \mathrm{M}\end{array}$ & $\begin{array}{l}\text { Portal cirrhosis } \\
\text { Ischaemic heart disease. } \\
\text { Broncho-pneumonia. No }\end{array}$ & $\overline{2}$ & $\begin{array}{l}\text { Nodal tachycardia } \\
\text { Atrial flutter }\end{array}$ & $\begin{array}{l}30 \text { minutes } \\
48 \text { hours }\end{array}$ & $\begin{array}{l}136 \\
170\end{array}$ & $\begin{array}{l}0 \\
+\end{array}$ & $\begin{array}{l}140 / 90 \\
130 / 90\end{array}$ & $\stackrel{?}{+}$ \\
\hline 9 & $60 \mathrm{M}$. & $\begin{array}{l}\text { recent infarct } \\
\text { Mild mitral stenosis and aortic } \\
\text { regurgitation. Ischaemic } \\
\text { heart disease W.P.W. }\end{array}$ & 2 & Atrial tachycardia & 36 hours & 160 & 0 & $120 / 70$ & $\mathbf{0}$ \\
\hline
\end{tabular}


diac output, and the largest increments occurred in the four patients with pre-conversion ventricular rates in excess of 180 beats per minute. The percentage change in cardiac output after conversion and its relationship to the rate of the arrhythmia is shown in the Chart. The greatest percentage increase in cardiac output was recorded in Case 1, who had a functionally normal heart and a very rapid tachycardia of 264 beats per minute. The critical heart rate for this series above which one could expect a significant increase in cardiac output appeared to be 160 beats per minute. All nine patients increased their stroke volume after conversion.

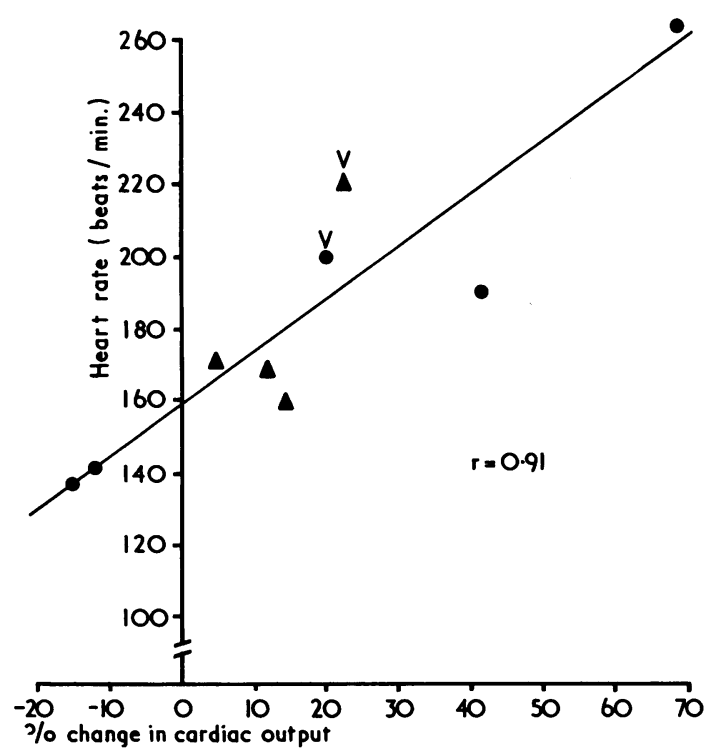

Percentage change in cardiac output after conversion to sinus rhythm, compared with the heart rate immediately before conversion. Dots indicate patients whose functional capacity was assessed as grade 0-I before the arrhythmia, and triangles those assessed as grade II (New York Heart Association, 1964). $V$ indicates the two patients with ventricular tachycardia. The regression line is derived from the reoression equation: heart rate $1.45 \times \%$ increase in cardiac output $+158, \mathrm{~N}=9, \mathrm{r}=0.91, \mathrm{P}<0.01$.

\section{Discussion}

Since the general acceptance of synchronized D.C. shock for most rapid arrhythmias, the decision regarding urgency has really amounted to whether or not cardioversion is indicated. The disadvantages of electrical conversion include the necessity in most cases for general anaesthesia and some uncommon risks inherent in the procedure itself, including the rare provocation of resistant ventricular fibrillation (particularly in digitalized patients), hypotension, systemic embolization, and pulmonary oedema (McDonald, 1965; Turner and Towers, 1965). Even when the necessary equipment and experienced staff are readily available, however, there may sometimes be doubt about the right moment to use electrical conversion, particularly in patients subject to repeated prolonged paroxysms of tachycardia. In this group there are two added disadvantages to the use of cardioversion. Firstly, an opportunity may be lost for the trial of a drug in the acute situation which may later be effective in prophylaxis against further paroxysms; and, secondly, as a result one may be committed to repeated cardioversions and hence repeated general anaesthetics. It is difficult to estimate what benefit is being withheld from these patients by delaying conversion.

Published studies of the effect of electrical conversion on cardiac output (Oram et al., 1963; Kahn et al., 1964; Halmos and Patterson, 1965; Morris et al., 1965; Reale, 1966; Killip and Baer, 1966; Rodman et al., 1966; Shapiro and Klein, 1968; Scott and Patterson, 1969) have been almost entirely concerned with patients in relatively well-controlled atrial fibrillation with ventricular rates below 120 . On the immediate effect of restoration of sinus rhythm in this group there is some disagreement. Some authors (Reale, 1965; Rodman et al., 1966) have noted an immediate increase in resting cardiac output, but most have found only an immediate improvement in the cardiac responses to exercise, with an increase in resting cardiac output after periods ranging from three hours (Morris et al., 1965) to a week or more later (Oram et al., 1963).

In the acute situation posed by rapid tachycardia one is more concerned with immediate results than with events up to a week later. Benchimol et al. (1965) found no immediate change in resting cardiac output after cardioversion in one patient with a ventricular tachycardia at a rate of 144 beats per minute. In another patient, who developed an atrial tachycardia at a rate of 180 per minute, they found that the cardiac output had fallen by $8 \%$ during the paroxysm. A study by Graettinger et al. (1964) included four patients in atrial fibrillation with ventricular rates greater than 120 . One hour after conversion these all showed an increase in cardiac output ranging from $7 \%$ in a patient with a preconversion rate of 185 to $62 \%$ in a patient with a preconversion rate of 206 , but the correlation with rate was not clear.

In our series a heart rate of about 160 beats per minute appears to be the critical level above which the arrhythmia causes an appreciable drop in cardiac output, and hence probably a good immediate result from cardioversion. No patients tolerating rapid arrhythmia badly-that is, with significant hypotension, cardiac failure, or chest pain-are included in our series. Such patients are converted to sinus rhythm without delay. In patients with a satisfactory clinical state whose ventricular rate is less than 160 , it is not unreasonable to withhold cardioversion for two to three days, giving the opportunity for a trial of antiarrhythmic drugs. Conversely, where the heart rate is appreciably higher we would apply electrical conversion much sooner.

\section{Results Compared}

Two types of tachycardia have been extensively investigated by other workers - that produced by electrically pacing the heart at rapid rates (Ross et al., 1965; Benchimol and Liggett, 1966; Braunwald et al., 1967) and exercised-induced tachycardia (Rushmer, 1959; Chapman et al., 1960; Reeves et al., 1961; Saltin and Sternberg, 1964; Braunwald et al., 1967). The effect on cardiac output of the rapid arrhythmias in our patients resembled quite closely the effect of electrical pacing at rapid rates, in that Benchimol and Liggett (1966) found that when the normal heart was paced at rates greater than 150 beats per minute the cardiac output began to fall.

Studies of cardiac output during severe exercise, however, have shown that increases may still be expected at rates up to 200 beats per minute (Reeves et al., 1961; Saltin and Sternberg, 1964). In the artificially paced situation stroke volume falls proportionately to increasing heart rate to maintain cardiac output at a fairly constant level over a wide range of rates (Braunwald et al., 1967). With exercise-induced tachycardia the stroke volume decreases to a less extent with increasing heart rate (Rushmer, 1959), and may even increase, particularly with exercise in the erect position (Chapman et al., 1960). Ventricular dimensions, similarly, have been found to be greater at any given heart rate when tachycardia is exercise-induced than when it is induced in the same heart at rest by pacing (Braunwald et al., 1967). Thus the higher stroke volumes during exercise are to be expected with increased venous return and the benefit of the Frank-Starling mechanism (Braunwald et al., 1967), but it is not clear why, in rapidpaced rhythm and spontaneous arrhythmia, a disproportionate decrease in stroke volume should begin at heart rates between 150 and 160 beats per minute.

Shortening of the diastolic filling period is often quoted as the factor limiting cardiac output in tachycardia (Benchimol and Liggett, 1966), and this is probably less pronounced in exercise-induced tachycardia, for then the velocity of shortening of myocardial fibres is greater and systole shorter than when 
the heart is paced to the same rate at rest (Braunwald et al., 1967). This factor alone seems insufficient to account for the relatively low critical rate in spontaneous arrhythmia, and possibly diminished ventricular acceptance of diastolic volume load also plays a part, in keeping with the observation that patients with reduced myocardial compliance due to hypertrophic or obliterative cardiomyopathy tolerate arrhythmia badly (Goodwin, 1970). A correctly timed atrial contraction is probably particularly important in these circumstances; and, similarly in arrhythmia following myocardial infarction, the importance of the loss of active atrial transport has been stressed (Fluck et al., 1967).

Cases 1, 8, and 9 of our series, who had presystolic atria! contraction before conversion, seemed to benefit as much from cardioversion as the others (Table II), implying that their atrial transport was not a particular asset. The numbers, however, are too few for this finding to be of significance. Also it is not certain that the return of a $P$ wave to the electrocardiogram in these patients necessarily meant immediate restoration of a normal left atrial contraction, certainly this is not always the case (Braunwald, 1964; Logan et al., 1965; Ikram et al., 1968). Experimental work with electrical pacing of the heart at varying rates has suggested that the gain in terms of cardiac output from atrial as opposed to ventricular stimulation is slight, but tends to be greater at increasing rates and in the abnormal heart (Benchimol and Liggett, 1966).

Clearly the ability of the individual patient to withstand any fall in cardiac output due to arrhythmia will depend not only on its degree and duration but also on other factors, particularly the state of the coronary and cerebral circulations and the presence or absence of valvular or myocardial disease. Our first patient was able to sustain for several weeks, at the age of 15 , a tachycardia of a rapidity which would not be tolerated by those in older age groups or with significant primary cardiovascular lesions.

We thank Mrs. Barbara Lea and the staff of the E.C.G. department, Sister J. Davies and the staff of the cardiac-catheter theatre, and Sister A. Gannicliffe and the staff of the coronary intensive care unit of the Liverpool Regional Cardiac Centre. We are indebted to Dr. T. Deegan for help with the statistical calculations.
This work was supported in part by Research Grant No. 92 from the Medical Research Committee of the United Liverpool Hospitals.

\section{REFERENCES}

Benchimol, A., Elis, J. G., Dimond, E. G., and Wu Teh-Lu. (1965) American Heart fournal, 70, 775

Benchimol, A., and Liggett, M. S. (1966). Circulation, 33, 933.

Braunwald, E. (1964). American fournal of Medicine, 37, 665.

Braunwald, E., Sonnenblick, E. H., Ross, J., jun., Glick, G., and Epstein, S. E. (1967). Circulation Research, 20, Suppl. No. 1, p. 44.

Chapman, C. B., Fisher, J. N., and Sproule, B. J. (1960). Fournal of Clinical Investigation, 39, 1208.

Fluck, D. C., et al. (1967). British Heart fournal, 29, 170.

Friedberg, C. K. (1966). Disease of the Heart, 3rd edn., p. 556. Philadelphia, Saunders.

Goodwin, J. F. (1970). Lancet, 1, 731.

Graettinger, J. S., Carleton, R. A., and Muenster, J. J. (1964). Fournal of Clinical Investigation, 43, 2290.

Halmos, P. B., and Patterson, G. C. (1965). British Heart fournal, 27, 719.

Hamilton, W. F., Moore, J. W., Kinsman, J. M., and Spurling, R. G. (1932) American fournal of Physiology, 99, 534 .

American fournal of Physiology, 99, 534.
Ikram, H., Nixon, P. G. F., and Arcan, T. (1968). British Heart fournal, $30,80$.

Kahn, D. R., Wilson, W. S., Weber, W., and Sloan, H. (1964). Fournal of Thoracic and Cardiovascular Surgery, 48, 898.

Killip, T., and Baer, R. A. (1966). Fournal of Clinical Investigation, 45, 658. Logan, W. F. W. E., Rowlands, D. J., Howitt, G., and Holmes, A. M. (1965). Lancet, $2,471$.

Lown, B., Amarasingham, $R$, and Neuman, J. (1962). Fournal of the American Medical Association, 182, 548.

McDonald, L. (1965). In Symposium on Advanced Medicine, ed. N. Compston, p. 351 . London, Pitman Medical.

Morris, J. J., jun., Entman, M., North, W. C., Kong, Y., and McIntosh, H. (1965). Circulation, 31, 670

New York Heart Association, Inc. (1964). Discases of the Heart and Blood Vessels, Nomenclature and Criteria for Diagnosis, 6 edn., p. 112. Boston, Little, Brown.

Oram, S., Davies, J. P. H., Weinbren, I., Taggart, P., and Kitchen, L. D. (1963). Lancet, 2, 159.

Reale, A. (1965). Circulation, 32, 214.

Reeves, J. T., Grover, R. F., Blount, S. G., jun., and Filley, G. F. (1961) fournal of Applied Physiology, 16, 283.

Rodman, T., Pastor, B. H., and Figueroa, W. (1966). American fournal of Medicine, 41, 249.

Ross, J., jun., Linhart, J. W., and Braunwald, E. (1965). Circulation, 32, 549. Rushmer, R. F. (1959). American fournal of Physiology, 196, 745.

Saltin, B., and Stenberg, J. (1964). Fournal of Applied Physiology, 19, 833.

Scott, M. E., and Patterson, G. C. (1969). British Heart Fournal, 31, 87.

Seldinger, S. I. (1953). Acta Radiologica, 39, 368

Shapiro, W., and Klein, G. (1968). Circulation, 38, 1074.

Turner, J. R. B., and Towers, J. R. H. (1965). Lancet, 2, 612.

\title{
Effect of Trimethoprim-Sulphamethoxazole on Typhoid and Salmonella Carriers
}

\author{
J. BRODIE,* M.D., D.P.H., F.R.C.PATH. ; I. A. MACQUEEN, $†$ M.D., D.P.H., D.S.C.H.E. \\ D. LIVINGSTONE, $\ddagger$ L.R.C.P.\& S. (ED., GLASG.), D.I.H., D.P.H.
}

British Medical fournal, 1970, 3, 318-319

\begin{abstract}
Summary: Four chronic typhoid carriers from the Aberdeen typhoid outbreak of 1964 were treated with trimethoprim-sulphamethoxazole. The male carrier remained clear of infection following treatment but the three female carriers, all with gall bladder abnormalities, remained excretors. A convalescent typhoid excretor also remained clear of infection after treatment as well as two other salmonella carriers, one of whom has been a chronic carrier for 24 years.
\end{abstract}

\section{Introduction}

The Aberdeen typhoid outbreak of 1964 (Walker, 1965) left a legacy of six chronic carriers of Salmonella typhi phage type 34 despite attempts to use ampicillin and other antibiotics to

* Consultant-in-Charge, the Laboratory, City Hospital, Aberdeen.

+ Medical Officer of Health, Aberdeen.

₹ Medical Officer of Health, County of Kincardine. clear convalescent carriers (Russell, Sutherland, and Walker, 1966). Since then two of the elderly carriers have died from other causes.

With the advent of trimethoprim-sulphamethoxazole (Septrin) it was decided that this would be worthy of trial, since the strain of $S$. typhi involved showed in-vitro sensitivity to this combination of synergistically active agents. Some possible success of its use in typhoid fever in Africa has been recorded (Pugsley, Mwanje, Pearson, and Blowers, 1969). The opportunity was taken also to assess its effects on a convalescent typhoid excretor and two chronic salmonella carriers. We here record the details of the investigations made with the co-operation of the patients involved who had the purpose of the trial fully explained to them.

\section{Patients Studied and Results}

Case 1.-A man aged 55 had remained stool-positive for $S$. typhi phage type 34 since the Aberdeen typhoid outbreak in 1964. 